\title{
An Examination of Social Networks on the Recruitment Process in the United Arab Emirates
}

\author{
Safeyya Al Shehi ${ }^{1}$, Lincoln Pettaway ${ }^{1}$, Lee Waller ${ }^{2} \&$ Sharon Waller ${ }^{2}$ \\ ${ }^{1}$ School of Business, American University of Ras Al Khaimah, Ras Al Khaimah, United Arab Emirates \\ ${ }^{2}$ School of Arts \& Sciences, American University of Ras Al Khaimah, Ras Al Khaimah, United Arab Emirates \\ Correspondence: Lee Waller, School of Arts \& Sciences, American University of Ras Al Khaimah, PO Box \\ 10021, Ras Al Khaimah, United Arab Emirates. Tel: 97-156-156-5977. E-mail: lee.waller@aurak.ac.ae
}

\author{
Received: December 5, 2015 Accepted: December 19, 2015 Online Published: January 12, 2016 \\ doi:10.5539/ass.v12n2p120 \\ URL: http://dx.doi.org/10.5539/ass.v12n2p120
}

\begin{abstract}
This study evaluates the effects of social networks on the recruitment of professional staff to Ras Al Khaimah's government and private sector within the United Arab Emirates (UAE). Questionnaires were administered to human resources employees who work at various levels of Ras Al Khaimah's government and private sector. A quantitative methodology was utilized for this study. The paper conducted a factor analysis for dimension reduction on the findings of a questionnaire submitted to selected businesses with Ras Al Khaimah in the United Arab Emirates. Findings indicated 5 underlying factors driving answers to the 24 questions included on the questionnaire. These 5 factors were labeled as (1) general perception, (2) convenience, (3) reliability, (4) international recruitment and (5) branding and marketing. These 5 underlying factors indicated that relationships exist between the variables.
\end{abstract}

Keywords: social networks, recruitment, highly-qualified employees, Ras Al Khaimah

\section{Introduction}

The Emirate of Ras Al Khaimah (RAK) is the fastest growing and most northern emirate in the U.A.E. (Alhebsi, Pettaway, \& Waller, 2015). Over the past decade RAK has become a destination for many tourist and investors. Numerous light and medium manufacturing firms, as well as, service industries are located throughout RAK. To maintain professional standards these firms seek highly trained professionals. The human resource departments in these organizations have often relied on traditional methods such as classified ads and recruitment agencies to recruit new employees. However, the use of these mediums has decreased over time. Subsequently, younger college graduates have begun to depend heavily on the use of social networks while actively pursuing employment opportunities. The use of the internet social networks sites over the past ten years has grown exponentially. For this reason companies and recruiters, throughout the region have had to utilize social networks to identify potential highly qualified candidates.

RAK government and semi-private sectors are routinely involved in the process of recruiting highly qualified employees. Social networks can positively influence the recruitment processes and can aid in the employment process for both of these sectors (De Run, Manickam, \& Jee, 2010). The increased use of social networks in other Emirates' may contribute to increased growth within both governmental and semi-private sectors in RAK. In recent years, many highly qualified individuals have begun to utilize social networks. For governmental and semi-private entities in RAK to remain competitive in attracting the interest of qualified applicants, consideration of ever emerging technology is a must.

\section{Review of the Literature}

This study examines the current practices within the RAK governmental and the semi-private sectors in utilizing social networks to recruit qualified human capital. Additionally, this study analyzed the underlying factors that support the use of social networks in the recruitment practices in RAK government and semi-private sectors. Many companies seek to find highly qualified employees. Noe (2012) explained that companies spent large amounts of money, resources and time in their recruitment efforts. Much of their efforts utilized various strategies to recruit new employees. Many companies, both public and private worldwide have found success in using social networks and have integrated these technologies into their daily operation (Headworth, 2011). 


\section{Research Design}

For the purpose of this paper, systems-thinking is considered within the tradition of human resources established by Argyis and Senge (Argyis, 1999; Bertalanffy, 1950; Jackson, 1995; Rosenblueth et al., 1943). Senge (1990) defines systems-thinking as "a discipline for seeing wholes. It is a framework for seeing interrelationships rather than independent variables. In this way systems-thinking supports the ability of one to recognize patterns of change rather than static 'snapshots' of a problem of dysfunction within an organization. It is a set of general principles" (p. 68). Due to the dynamic nature of systems theory, ontological implications can be derived based on certain theoretical applications of systems theory when used within a real-world context. However, theoretical systems models can also be used as epistemological devices to explain and explore current real world perspectives (Jackson, 1995).

Systems-thinking is one of the central tenets of human resource development and by Senge's (1999) definition it is "a conceptual framework, a body of knowledge and tools that have been developed over the past fifty years to make patterns clearer and to see how to change them effectively" (p. 7). "Systems-thinking" is rooted in a tradition that focuses on operational solutions that are primarily developed from a need to improve processes related to logistical manufacturing and business needs (Jackson, 1995).

\subsection{Research Approach}

The research approach selected for this dissertation is deductive in nature. The quantitative research method utilized in this dissertation is factor analysis. Dunteman (1989) identified factor analysis as a methodology to reduce a large number of variables into underlying dimensions. The indication of underlying factors was deemed an appropriate methodology for identifying relationships between the identified variables. Factor eigenvalues at or above 1.0 were deemed significant.

Dunteman (1989) established four assumptions for factor analysis. The four assumptions follow:

1) The data sets must not contain outliers.

2) The sample size must be adequate and the case must be greater than the factor.

3) The model must be linear in nature.

4) Interval data are assumed.

Again, the researcher examined each of these assumptions to provide the informed consumer appropriate information by which to assess the findings of the study. The usefulness of the research was left to the determination of the informed reader.

\subsection{Research Strategy}

Dunteman, (1989) explained that quantitative research methods provide the researcher with the opportunity to answer questions that pertain to the relationship of variables being studied. Dunteman (1989) went even further to explain that research strategies should be designed to support the collection of the data required to appropriately address the research question as well as the research objective. Factor analysis was utilized to examine the relationships between all variables within this study. The factor analysis employed data reduction techniques to identify underlying latent variables that are reflected in the observed variables. Factors with initial Eigenvalues above 1.0 were considered significant (Waller, S., \& Waller, R., 2014).

\subsection{Research Methodology}

Descriptive analysis and factor analysis were utilized to address the research questions and research hypotheses employed in the study. Data were collected through the administration of a survey designed to examine the utilization of social networks within the business context.

\subsection{Research Questions}

This study answered the following research questions.

1) What are the responses of Ras $\mathrm{Al}$ Khaimah human resources personnel related to the usability of social networks, reliability of social networks, branding of marketing and corporations, change in the nature of recruitment, and effective recruitment through the social networks?

2) Do relationships exist between or among the responses of Ras Al Khaimah human resources personnel related to the usability of social networks, reliability of social networks, branding of marketing and corporations, change in the nature of recruitment, and effective recruitment through the social networks? 


\subsection{Research Hypotheses}

The following null and alternate hypotheses were utilized to guide this study and support the analysis required in Research Question 2.

Ho1 No relationships exist between or among the responses of Ras Al Khaimah human resources personnel related to the usability of social networks, reliability of social networks, branding of marketing and corporations, change in the nature of recruitment, and effective recruitment through the social networks.

Ha1 Relationships exist between or among the responses of Ras Al Khaimah human resources personnel related to the usability of social networks, reliability of social networks, branding of marketing and corporations, change in the nature of recruitment, and effective recruitment through the social networks.

\subsection{Data Collection}

Data for the study were collected through the administration of a 24-question survey developed to examine the impact of social networks on recruitment at RAK semi-government and private sector entities. The surveys were designed for persons currently or previously employed in management and leadership positions. Participants in the survey were selected based on standard convenience sampling techniques. Participation in the survey was completely voluntary. Participants agreed by signature to the utilization of the survey results as required for the completion of the study. Information provided on the survey documents was converted into an Excel document. The Excel document was then formatted and copied to a Statistical Packages for the Social Sciences (SPSS) Version 22.0.0 spreadsheet for analysis. The data were then stored on a flash drive kept under control of the researcher to protect the identity and anonymity of the respondents.

\subsection{Reliability, Validity and Sample Size}

Reliability of the survey responses was examined utilizing the Chronbach's alpha. Chronbach's alpha is a measure of scale reliability (Institute for Digital Research and Education, 2015). A reliability coefficient of 0.70 or higher is deemed to be acceptable. Validity of the survey instrument was established through the factor analysis conducted in answer to research question 2 (Stapleton, 1997). Factors having eigenvectors at or above 1.0 were deemed significant. The adequacy of sampling size was assessed using the Kaiser-Meyer-Olkin measure of sampling adequacy. Significance was set at 0.05 .

\subsection{Research Ethics}

The researcher maintained the anonymity of respondents. Once surveys were received, responses were entered into an Excel spreadsheet. The names and other identifiable demographics were not included in the Excel spreadsheet. When this information was translated into SPSS, no identifiable demographics were included.

\subsection{Limitations and Delimitations}

This study was limited by the following factors.

1) Data included in the study were self-reported by individuals human resources personnel. As such, all the traditional limitations of self-reported data apply.

2) The data were available only for the spring 2015 semester. No data were available prior to this time.

3) The researcher delimited the study as follows.

4) The study was restricted to data retrieved utilizing the survey instrument.

5) The collection of information was delimited to convenience sampling only.

6) Only human resources personnel were included in the study.

7) The research examined only the usability of social networks, reliability of social networks, branding of marketing and corporations, change in the nature of recruitment, and effective recruitment through the social networks.

\subsection{Assumptions}

The following assumptions were made for this study.

1) The data are accurate and correctly recorded.

2) The data are usable and appropriate for this study.

3) Examination of the data has the potential to impact future practice and research. 


\section{Findings and Analysis}

This study conducted factor analysis on all the indicated variables to examine underlying associations. SPSS statistical analysis software was utilized to conduct the indicated examinations. The research examined relationships and factors associated with the responses of Ras Al Khaimah human resources personnel related to the usability of social networks, reliability of social networks, branding of marketing and corporations, change in the nature of recruitment, and effective recruitment through the social networks.

\subsection{Research Objectives}

The following research objectives guided the study:

1) To ascertain which social networks sites were most commonly used in recruitment at RAK corporations and to determine to what extent social networks led to effective recruitment.

2) To determine if the use of social networks helps to increase awareness of the organization.

3) To identify more effective ways to utilize social networks in recruitment of human capital.

Figure 1 provides the flow of survey results through four major areas of interest.

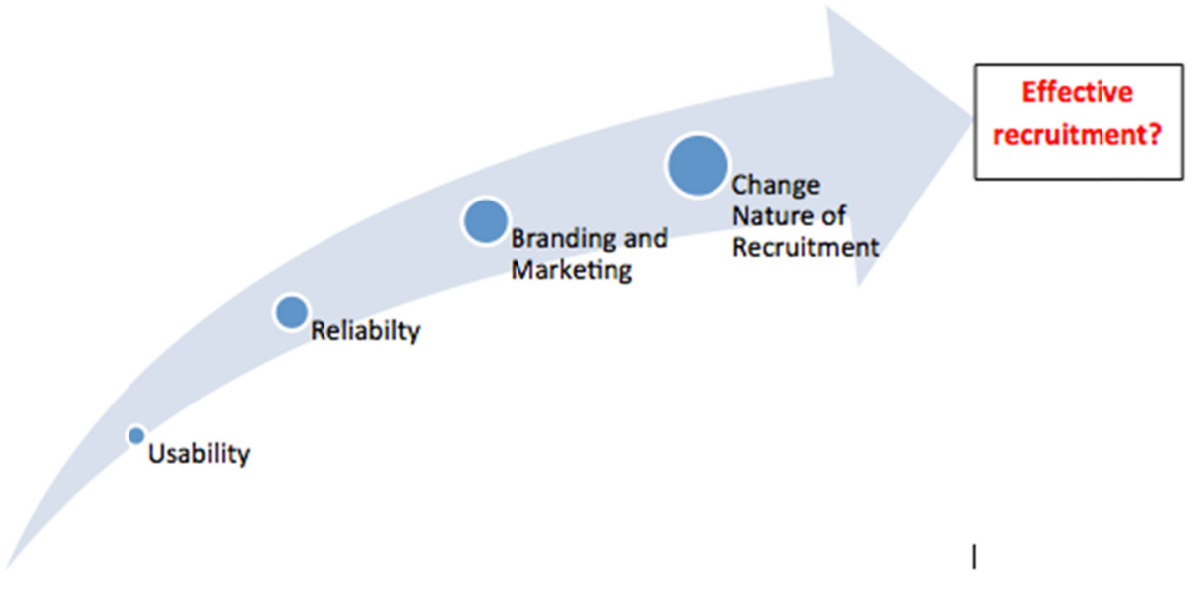

Figure 1. Pathway to effective recruitment

The questionnaire utilized in the study was designed to examine these four areas as they map to the establishment of effective recruitment. Accordingly, a cross mapping matrix was established to guide the evaluation of the assessment findings.

\subsection{Research Question 1}

The first research question called for an analysis of the average response scores for each of variables relating to social networks, reliability of social networks, branding of marketing and corporations, change in the nature of recruitment, and effective recruitment through the social networks. Accordingly the required descriptive statistics are provided in Table 1.

Table 1. Responses to questionnaire concerning the impact of social networks

\begin{tabular}{cccccccc}
\hline Questions & N & Mean & Std. Dev. & Min & Max & Skewness & Kurtosis \\
\hline 1. Recruitment LinkedIn & 29 & 3.52 & 1.405 & 1 & 5 & -0.702 & -0.562 \\
2. Recruitment Facebook & 29 & 2.72 & 1.461 & 1 & 5 & 0.075 & -1.319 \\
3. International Facebook & 29 & 2.07 & 0.884 & 1 & 5 & -0.141 & -1.748 \\
4. International Whatsup & 29 & 1.09 & 0.860 & 1 & 5 & 0.571 & -0.466 \\
5. Recruitment Inestgram & 29 & 2.00 & 1.000 & 1 & 5 & 1.151 & 1.607 \\
6. Recruitment Twitter & 29 & 1.90 & 0.860 & 1 & 5 & 0.571 & -0.466 \\
7. Recruitment Social networks & 29 & 3.55 & 1.021 & 1 & 5 & -0.475 & 0.037 \\
\hline
\end{tabular}




\begin{tabular}{cccccccc}
\hline Questions & N & Mean & Std. Dev. & Min & Max & Skewness & Kurtosis \\
\hline 8. Convenience & 29 & 3.52 & 1.056 & 1 & 5 & -0.49 & -0.298 \\
9. Information on Candidates & 29 & 3.21 & 1.346 & 1 & 5 & -0.311 & 0.434 \\
10. More Effective Recruitment & 29 & 2.83 & 1.391 & 1 & 5 & -0.012 & 0.434 \\
11. Improved Global Effectiveness & 29 & 3.59 & 1.323 & 1 & 5 & -0.547 & -0.637 \\
12. Branding \& Marketing & 29 & 3.52 & 1.214 & 1 & 5 & -0.107 & -1.084 \\
13. Improved Communication & 29 & 3.86 & 0.789 & 1 & 5 & 0.257 & -1.320 \\
14. Candidate Communication & 29 & 3.69 & 1.072 & 1 & 5 & -0.253 & -1.142 \\
15. Share Business News & 29 & 3.79 & 1.048 & 1 & 5 & 0.045 & -1.547 \\
16. Enhance Publicity & 29 & 3.86 & 1.156 & 1 & 5 & -0.755 & -0.259 \\
17. Target Global Talent & 29 & 3.34 & 0.897 & 1 & 5 & -0.134 & 0.810 \\
18. Facebook Branding & 29 & 3.03 & 1.569 & 1 & 5 & -0.001 & -1.537 \\
19. Twitter Branding & 29 & 2.72 & 1.386 & 1 & 5 & 0.362 & -0.916 \\
20. LinkedIn Branding & 29 & 3.41 & 1.570 & 1 & 5 & -0.632 & -1.168 \\
21. Whatsup Branding & 29 & 2.59 & 1.053 & 1 & 5 & -0.244 & -1.081 \\
22. Inestgram Branding & 29 & 3.24 & 1.123 & 1 & 5 & -0.026 & -0.971 \\
23. Reliability of Social networks & 29 & 2.69 & 0.967 & 1 & 5 & -0.328 & 0.489 \\
24. Eliminate Need for Recruitment & 29 & 3.24 & 1.244 & 1 & 5 & -0.255 & -0.796 \\
\hline
\end{tabular}

Responses on the questionnaire ranged from a high of 3.86 on question 13 improved communication and question 16 enhanced publicity to a low of 1.09 on question 4 international recruitment using Whatsup. Preliminary review of the scores indicates that the higher scores were awarded to the more general questions indicating that the use of social networks to recruit potential candidates is occurring. Additionally, social networks appear to be utilized in the normal operations of the businesses responding to the questionnaire. The lower scores tended to be in the utilization of specific applications. This finding likely indicate the importance of social networks in recruitment and functioning of the business entity while demonstrating the utilization of a wide range of digital resources and tools.

Skewness and kurtosis were examined to ascertain the likelihood that the responses to the questions were approximately normally distributed (NIST/SEMATECH, 2015). Skewness variables of 0.000 are consistent with normality. Kurtosis values utilized by SPSS of 0.000 are also consistent with normality. Values for either ranging more than 3.000 units to 0.000 are considered outside the range of normality. Review of the skewness and kurtosis values for the responses for each question indicates that the responses fall into the approximately normal range.

\subsection{Research Question 2}

Research question 2 examined underlying relationships between or among the responses of Ras Al Khaimah human resources personnel related to the usability of social networks, reliability of social networks, branding of marketing and corporations, change in the nature of recruitment, and effective recruitment through the social networks. Prior to the examination of the associated null and alternate hypotheses, the study examined sampling adequacy and sphericity of the data set. These findings are provided in Table 2.

Table 2. Kmo and bartlett's test

\begin{tabular}{lll}
\hline Test & Description & Significance \\
\hline Kaiser-Meyer-Olkin Measure of Sampling Adequacy & Measure of Sampling & 0.327 \\
Bartlett's Test of Sphericity & Approximate Chi-Square & 934.5 \\
& df & 276 \\
& Sig. & $>0.001$ \\
\hline
\end{tabular}


The Kaiser-Meyer-Olkin Measure of Sampling Adequacy indicates that the sample was adequate for the purposes of factor analysis. The Bartlett's Test of Sphericity indicates that some relationships are likely to exist between or among the indicated variables. Accordingly, the null hypothesis is rejected in favor of the alternate hypothesis. This finding supports conducting factor analysis on the indicated data. Findings for the factor analysis are provided in Table 3.

Table 3. Total variance explained

\begin{tabular}{ccccccc}
\hline \multirow{2}{*}{ Component } & \multicolumn{3}{c}{ Initial Eigenvalues } & \multicolumn{3}{c}{ Extraction Sums of Squared Loadings } \\
\cline { 2 - 6 } & Total & \% of Variance & Cumulative \% & Total & \% of Variance & Cumulative \% \\
\hline 1 & 11.377 & 47.405 & 47.405 & 11.377 & 47.405 & 47.405 \\
2 & 3.724 & 15.515 & 62.921 & 3.724 & 15.515 & 62.921 \\
3 & 2.158 & 8.993 & 71.913 & 2.158 & 8.993 & 71.913 \\
4 & 1.670 & 6.959 & 78.872 & 1.670 & 6.959 & 78.872 \\
5 & 1.287 & 5.364 & 84.236 & 1.287 & 5.364 & 84.236 \\
\hline
\end{tabular}

Extraction Method: Principal Component Analysis

Table 3 provides the total variance explained by the model. Five factor components were identified with eigenvalues of $11.377,3.724,2.158,1.670$ and 1.287 respectively. These 5 identified factors explained $84.236 \%$ of the variance in the data set. The identification of 5 factor components with eigenvalues at or above 1.0 confirmed rejection of the null hypothesis, Ho1. The alternate hypothesis, Ha1, is accepted. Associations exist between or among the responses of Ras Al Khaimah human resources personnel related to the usability of social networks, reliability of social networks, branding of marketing and corporations, change in the nature of recruitment, and effective recruitment through the social networks (Waller. S, \& Waller, R., 2014).

A scree plot is provided in Figure 2. The scree plot visually confirms the percentage of variance in the 24 variables explained by the 5 identified variables. The slope of the curve does appear to begin leveling out after 5 factors (Waller \& Lumadue, 2013).

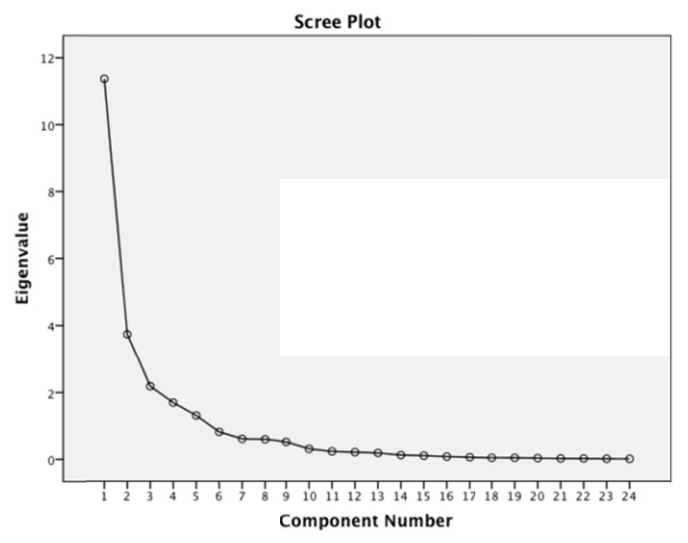

Figure 2.

The component matrix for each of the identified factors is provided in Table 4.

The first factor appeared to be an overall impression of the utilization of social networks for recruitment and business purposes. The second factor related to the convenient utilization of available digital tools. The third factor provided insight into the reliability of social networks to accomplish its intended purpose. The fourth factor concerned the utilization of social networks for international recruitment. The fifth and final factor addressed improved branding and marketing efforts. Accordingly, the 5 identified factors were named (1) general perception, (2) convenience, (3) reliability, (4) international recruitment and (5) branding and marketing. 
Table 4. Component matrix

\begin{tabular}{lccccc}
\hline & 1 & 2 & 3 & 4 & 5 \\
\hline 1. Recruitment LinkedIn & 0.801 & -0.145 & -0.125 & -0.267 & 0.384 \\
2. Recruitment Facebook & 0.717 & -0.465 & 0.107 & 0.014 & -0.275 \\
3. International Facebook & 0.484 & -0.670 & 0.217 & 0.105 & 0.009 \\
4. International Whatsup & 0.516 & -0.680 & 0.170 & 0.299 & -0.116 \\
5. Recruitment Inestgram & 0.542 & -0.595 & 0.189 & 0.353 & 0.034 \\
6. Recruitment Twitter & 0.606 & -0.619 & 0.123 & 0.195 & -0.202 \\
7. Recruitment Social networks & 0.588 & 0.170 & -0.529 & 0.485 & 0.052 \\
8. Convenience & 0.476 & 0.535 & -0.453 & 0.319 & 0.231 \\
9. Information on Candidates & 0.827 & -0.019 & -0.234 & -0.217 & 0.331 \\
10. More Effective Recruitment & 0.887 & 0.086 & 0.056 & -0.054 & 0.339 \\
11. Improved Global Effectiveness & 0.818 & 0.344 & 0.258 & 0.185 & 0.042 \\
12. Branding \& Marketing & 0.681 & 0.203 & 0.129 & -0.503 & -0.281 \\
13. Improved Communication & 0.658 & 0.423 & -0.064 & 0.008 & -0.304 \\
14. Candidate Communication & 0.895 & 0.069 & 0.153 & -0.198 & 0.009 \\
15. Share Business News & 0.767 & 0.361 & 0.211 & -0.316 & -0.271 \\
16. Enhance Publicity & 0.646 & 0.562 & 0.315 & 0.091 & -0.297 \\
17. Target Global Talent & 0.111 & 0.645 & 0.555 & 0.252 & 0.290 \\
18. Facebook Branding & 0.920 & 0.023 & -0.028 & -0.140 & 0.029 \\
19. Twitter Branding & 0.849 & 0.022 & -0.127 & -0.257 & -0.041 \\
20. LinkedIn Branding & 0.891 & -0.154 & 0.057 & 0.024 & 0.275 \\
21. Whatsup Branding & 0.858 & -0.246 & -0.071 & 0.373 & 0.106 \\
22. Inestgram Branding & 0.568 & 0.213 & -0.362 & -0.026 & -0.468 \\
23. Reliability of Social networks & -0.334 & 0.029 & 0.791 & 0.052 & 0.142 \\
24. Eliminate Need for Recruitment & 0.331 & 0.421 & 0.341 & 0.472 & 0.143 \\
\hline
\end{tabular}

Findings were listed under two research questions and a set of null and alternate hypotheses. Research question 1 provided descriptive information for the data set. Research question 2 examined the existence of relationships between or among the responses of Ras Al Khaimah human resources personnel related to the usability of social networks, reliability of social networks, branding of marketing and corporations, change in the nature of recruitment, and effective recruitment through the social networks. Findings indicated that relationships between the variables do exist. Additionally, five underlying factors appeared to be driving the responses to the survey. These 5 factors were labeled as (1) general perception, (2) convenience, (3) reliability, (4) international recruitment and (5) branding and marketing. Conclusions and recommendations associated with the findings follow.

\section{Conclusions and Recommendations}

An examination of the descriptive analysis data revealed the existence of a relationship between social networks on the recruitment impact of professionals staffed by human resource personnel operating within the Emirate of Ras Al Khaimah. This study's findings clearly revealed the existence of a relationships between the responses of Ras Al Khaimah human resources personnel and the usability of social networks, reliability of social networks, branding of marketing and corporations, change in the nature of recruitment, and effective recruitment as a result of the utilization of social networks. This study's findings indicated that significant relationships between the variables do exist. Additionally, five underlying factors appeared to be driving the responses to the survey. These 5 factors were labeled as (1) general perception, (2) convenience, (3) reliability, (4) international recruitment and (5) branding and marketing. 
Five factor components were identified with eigenvalues of $11.377,3.724,2.158,1.670$ and 1.287 respectively. These 5 identified factors explained $84.236 \%$ of the variance in the data set. The identification of 5 factor components with eigenvalues at or above 1.0 confirmed rejection of the null hypothesis, Ho1. The alternate hypothesis, Ha1, is accepted. Associations exist between or among the responses of Ras Al Khaimah human resources personnel related to the usability of social networks, reliability of social networks, branding of marketing and corporations, change in the nature of recruitment, and effective recruitment through the social networks.

The highest utilized recruitment technology was LinkedIn with a standard deviation of 1.4. Followed by Facebook, 2.7 and Whatsup at 1.09, respectively. Whatsup was founded in 2009 and as of January 2015 became one of the most used applications globally, with more than 800 million active users. Facebook, launched in 2004, has over 1.44 billion users as of March 2015. LinkedIn, was launched on May of 2003, and as of May 2013 had over 259 million users. These statistics support the popularity of social networks in the field of human resources. These findings substantiate the utilization of social networks within the recruitment process of RAK government and semi-private sector. The descriptive analysis proved very informative and revealed several very important facts. The data provide within the component matrix also suggests that social networks are being used for professional and alternative ways beyond their original designed intentions. In this way the changing nature of recruitment is not only mediated by social networks network technologies, but also transformed and mat possibly be replaced in the future by an interactive technological entirely.

\section{Implications}

A holistic review of this analysis, allows for a thorough understanding, not only the changing nature of the social networks network within the field of human resource recruitment, but also the impact which globalization has also had on the field of human resource recruitment (Pettaway, Waller, \& Waller, 2016). The findings in this study also suggest that future technologies not yet invented, may have the potential to create a disruption that will transform the recruitment process if not the entire field of human resources completely (Ignatius \& Ramayah, 2005). Although other researchers consider the effects of technology on the recruitment process, few have focused on the more recent technological applications specified within this study. Few studies have also considered the exponential rate of change by which new technologies have been employed by recruitment personal. The rate of change within the usage of these technologies must not be considered alone. The rate of change between each new application utilized must also be considered significant. This study's findings also suggest that it is important that organizations directly involved with the recruitment process proved training, time and other resources to personal engaged in recruitment activities due these technologies ability to provide firms/employers with a competitive advantage.

\section{References}

Alhebsi, A., Pettaway, L., \& Waller, L. (2015). A history of education in the United Arab Emirates and Trucial Shiekdoms. The Global eLearning Journal, 4(1). Retrieve from https://globalelearningjournal.files. wordpress.com/2010/11/a-history-of-education-in-the-united-arab-emirates-and-trucial-sheikdoms.pdf

Argyis, C. (1999). On organizational learning (2nd ed.). United Kingdom: Blackwell Publishing.

Bertalanffy, L. (1950). The theory of open systems in physics and biology. Science, New Series, 111(2872), 23-29. http://dx.doi.org/10.1126/science.111.2872.23

De Run, E. C., Manickam, E., \& Jee, T. W. (2010). Testing Real World Advertisements Language Cues Impact on Dominant and Non-Dominant Ethnic Groups: Comparing Malays and Indians in Malaysia. International Journal of Business and Society, 11(2), 71.

Dunteman, G. H. (1989). Principal Components Analysis. Newbury Park, CA: Sage.

Headworth, A. (2011). Smart social networks recruitment strategies (1st ed.). London, UK: Ark Group.

Ignatius, J., \& Ramayah, T. (2005). An empirical investigation of the course website acceptance model (CWAM). International Journal of Business and Society, 6(2), 69-82.

Institute for Digital Research and Education. (2015). What does the Cronbach's alpha mean? Retrieved May 8 , 2015, from http://www.ats.ucla.edu/stat/spss/faq/alpha.html

Jackson, M. (1995). Beyond the fads: System thinking for managers. Systems Research, 12(1), 25-42. http://dx.doi.org/10.1002/sres.3850120106

NIST/SEMATECH e-Handbook of Statistical Methods. (2015). Retrieved May 8, 2015, from http://itl.nist.gov/div898/handbook/eda/section3/eda35b.htm 
Noe, R. (2012). Human resource management (1st ed.). New York, NY: McGraw-Hill Irwin.

Pettaway, L., Waller, L., \& Waller, S. (2016, in press). Surveying organizational effectiveness: A case study from the United Arab Emirates. Journal of Organizational Culture, Communication and Conflict.

Raj, A. (2010). Recruiting with social networks: social networks's impact on recruitment and hr (1st ed.). New York, NY: McGraw-Hill Irwin.

Rosenblueth, A., Wiener, N., \& Bigelow, J. (1943). Behavior, purpose and teleology. Philosophy of Science, 10, 18-24. http://dx.doi.org/10.1086/286788

Senge, P. (1990). The fifth discipline: The art and practice of the learning organization. New York: Doubleday/Currency. http://dx.doi.org/10.1108/eb025496

Stapleton, C. (1997, January). Basic concepts in exploratory factor analysis (EFA) as a tool to evaluate score validity: A right-brained approach. Retrieved May 8, 2015, from http://ericae.net/ft/tamu/Efa.htm

Waller, L., \& Lumadue, R. (2013). Factor Analysis (1st ed.). Cupertino, CA: Apple iTunes Connect. Retrieved from https://itunes.apple.com/us/book/factor-analysis/id656956844?ls=1

Waller, S., \& Waller, L. (2014). Alternative disciplinary placement in Texas. The Global eLearning Journal, 3(1). Retrieve from http://www.theglobalelearningjournal.org/wp-content/uploads/2010/11/Alternative-Disciplina ry-Placements-in-Texas1.pdf

\section{Copyrights}

Copyright for this article is retained by the author(s), with first publication rights granted to the journal.

This is an open-access article distributed under the terms and conditions of the Creative Commons Attribution license (http://creativecommons.org/licenses/by/3.0/). 